\title{
Construction of Hydroxyapatite Nanoceramics with High Mechanical Strength and Efficiency in Promoting the Spreading and Viability of Osteoblasts
}

\author{
WU Yonghao, LI Xiangfeng, ZHU Xiangdong, ZHANG Xingdong \\ (National Engineering Research Center for Biomaterials, Sichuan University, Chengdu 610064, China)
}

\begin{abstract}
The present study focuses on the construction of HA nanoceramics with excellent mechanical property and osteogenic activity, and the correlation between HA precursor powders and resulting ceramics. Three precursor powders were used, i.e. HA-40 synthesized at $40{ }^{\circ} \mathrm{C}$, HA-40PEG synthesized at $40{ }^{\circ} \mathrm{C}$ with PEG as a template, and HA-80 synthesized at $80{ }^{\circ} \mathrm{C}$. The results showed that grain sizes of three HA ceramics prepared by HA-40, HA-40PEG, and HA-80 precursors were $(217.87 \pm 57.53),(123.22 \pm 20.16)$, and (316.65 \pm 68.91$) \mathrm{nm}$, respectively. It demonstrated that compared with HA-40 and HA-80, HA-40PEG was more beneficial for fabricating HA nanoceramics. Among three resulting ceramics, HA-40PEG displayed the highest comprehensive strength ( $\sim 300 \mathrm{MPa})$. In addition, the nano-scale HA-40PEG ceramics promoted better cell spreading and proliferation than those of submicro-scale HA-40 and HA- 80 ceramics. These findings suggest that the preparation of HA precursor powders plays an important role in fabricating HA nanoceramics with simultaneous improvement of mechanical and biological properties.
\end{abstract}

Key words: hydroxyapatite; nanoceramics; initial powder; density; cellular viability

As the main inorganic component in human bone and tooth, hydroxyapatite (HA) presents good biocompatibility and bioactivity, and has been widely used for biomedical applications, especially in the orthopedic field ${ }^{[1-3]}$. However, the confliction between the mechanical strength and biological performance of HA ceramic limits its further utilization for bone repair at load-bearing sites ${ }^{[4-6]}$. Generally, higher sintering temperature leads to increased mechanical strength of HA ceramic, but decreased bioactivity due to the crystal perfection and loss of microporosity ${ }^{[7-9]}$. Recently, nanoceramics have aroused researchers' great interest because of the special nano-scale effect on the mechanical and biological properties ${ }^{[1,5]}$. According to Hall-Petch theory, the mechanical properties (i.e. hardness and toughness) would increase with the decreasing grain size ${ }^{[10-11]}$. Moreover, HA nanoceramics exhibit higher bioactivity than the submicro ceramics, due to their high specific surface area, surface nanotopography and lattice defects ${ }^{[1]}$. Thus, preparation of HA nanoceramics is often considered as an effective way to solve the contradiction between mechanical enhancement and bioactivity improvement.
To the best of our knowledge, the properties of the precursor powder and sintering processes are two key factors to affect the performances of the resulting ceramics. Up to now, many sintering techniques have been developed to fabricate HA nanoceramics, such as spark plasma sintering ${ }^{[12-14]}$, microwave sintering ${ }^{[5,15]}$, hot pressure sintering ${ }^{[16-17]}$, two-step sintering ${ }^{[18-20]}$ and so on. Among them, microwave sintering seems to be the most attractive method, due to its rapid, highly efficient and low energy cost process. Thuault et al. employed microwave sintering method to fabricate HA dense ceramics with nanoscale grain size and high mechanical performance successfully in a short time ${ }^{[21]}$. In our previous studies, biphasic calcium phosphate (BCP) ceramics with nanocrystalline structure were successfully fabricated by microwave sintering, which not only promoted the adhesion, proliferation, and osteogenic differentiation of ost. eoblasts in vitro, but also presented excellent osteoinductivity and bone regenerative ability in vivo ${ }^{[1,22]}$. However, the simultaneous enhancement of mechanical strength and bioactivity has not been well solved in HA nanoceramics. Mostly, HA precursor powders with needle-like

Received date: 2020-07-14; Revised date: 2020-08-08; Published online: 2020-08-28

Foundation item: National Key Research and Development Program of China (2016YFC1102000, 2016YFC1102003); Sichuan Science and Technology Innovation Team of China (2019JDTD0008).

Biography: WU Yonghao(1990-), male, PhD candidate. E-mail: hpu11wyh@163.com 吴永豪(1990-), 男, 博士研究生. E-mail: hpu11wyh@163.com

Corresponding author: ZHU Xiangdong, professor. E-mail: zhu_xd1973@scu.edu.cn 朱向东, 研究员. E-mail: zhu_xd1973@scu.edu.cn 
morphology could hinder the densification during the sintering process of ceramics ${ }^{[23]}$. It was found that the morphology of HA precursor powders could influence the density and mechanical strength of the ceramics ${ }^{[24]}$. Also, the synthesizing or calcining temperature would influence the crystallinity of the precursor powder, and it seems that the low crystallinity powder favored the densification process ${ }^{[25]}$. Thus, it need be further understood that the influences of the features of HA precursor powders (including morphology, particle size, crystallinity, specific surface area, etc.) on the properties of the resulting ceramics.

The present study attempted to construct HA nanoceramics with high mechanical strength by optimizing the initial powder, and investigated their efficiency in cellular viability. Firstly, three different HA precursor powders were synthesized, and their morphologies, size distributions, crystallinities, and specific surface areas were characterized. Then, the surface topography, phase composition, surface wettability, and mechanical strength of the resulting ceramics were investigated. Finally, the in vitro cell co-culturing with HA nanoceramics were performed to evaluate their cellular viability.

\section{Materials and methods}

\subsection{Material preparation}

HA precursor powders were prepared by wet chemical precipitation method as mentioned before ${ }^{[1]}$. In short, the same amount of $\mathrm{Ca}\left(\mathrm{NO}_{3}\right)_{2}\left(0.85 \mathrm{~mol} \cdot \mathrm{L}^{-1}\right)$ and $\left(\mathrm{NH}_{4}\right)_{2} \mathrm{HPO}_{4}$ $\left(0.50 \mathrm{~mol} \cdot \mathrm{L}^{-1}\right)$ solutions were mixed, and the $\mathrm{pH}$ was kept at $\sim 10.0$ by adding $\mathrm{NH}_{4} \mathrm{OH}$. After reaction, the precipitations were aged, washed, dried, and sieved. Three HA precursor powders were synthesized by using the different reactive conditions. For HA-40, the synthetic temperature was $40{ }^{\circ} \mathrm{C}$. For HA-40PEG, the synthetic temperature was $40{ }^{\circ} \mathrm{C}$, and polyethylene glycol (PEG) 6000 was used as template. For HA-80, the synthetic temperature was $80{ }^{\circ} \mathrm{C}$. Next, HA compacts $(\phi 14 \mathrm{~mm} \times$ $3 \mathrm{~mm}$ ) were fabricated by uniaxial pressing at $10 \mathrm{MPa}$, and then cold isostatic pressing at $250 \mathrm{MPa}$ for $5 \mathrm{~min}$. A microwave assisted sintering method was used to sinter the HA ceramics ${ }^{[5,15]}$, adopting the similar sintering process with our previous study (sintered at $1100{ }^{\circ} \mathrm{C}$ for $8 \mathrm{~min}$ at heating rate of $\left.100{ }^{\circ} \mathrm{C} \cdot \mathrm{min}^{-1}\right)^{[22]}$.

\subsection{Material characterization}

The morphologies of the HA precursor powders and resulting ceramics were observed by a scanning electron microscope (SEM, S-4800N, Hitachi, Japan). The phase composition and crystal structure of the samples were analyzed using X-ray diffraction (XRD, Philips $\chi$ 'Pert 1
X-ray diffractometer, Netherlands), where the measured angle was collected from $20^{\circ}$ to $60^{\circ}$ at a step size of $0.02^{\circ}$. The crystallinity $\left(X_{\mathrm{c}}\right)$ of the samples were calculated by the following equation:

$$
X_{\mathrm{c}}=1-\left(V_{112 / 300} / I_{300}\right)
$$

Where $I_{300}$ represents the intensity of (300) diffraction peak, $V_{112 / 300}$ is the intensity of the hollow between (112) and (300) reflections ${ }^{[7]}$.

The chemical groups of the samples were analyzed using a Fourier transform infrared spectrophotometer (FT-IR, Nicolet 6700, Thermo, USA). Infrared spectra of the HA precursor powders were used to assess the crystallinity index of the samples, which was calculated as the sum of the peak intensities at 602 and $563 \mathrm{~cm}^{-1}$ divided by the valley intensity between the two peaks ${ }^{[26]}$. Index of mineral maturity of the HA precursor powders was obtained by calculating the ratio of the area integrated intensity of phosphate group at $1030 \mathrm{~cm}^{-1}$ (apatite domain) to that at $1110 \mathrm{~cm}^{-1}$ (non-apatite domain) ${ }^{[27]}$. Particle size distributions of the HA precursor powders were tested in a laser scattering-based particle sizer (Mastersizer Micro, Malvern, Worcestershire, UK). Specific surface areas of the powders were measured by Nitrogen adsorption method (Gemini VII 2390t, Micromeritics, USA). Surface wettability of the HA ceramics was characterized by a water contact angle measurement machine (IL4200, KRÜSS $\mathrm{GmbH}$, Germany). The surface topography of the ceramics was examined by an atomic force microscopy (AFM; Asylum Research, MFP-3D, Oxford Instruments, UK). The average surface roughness $(R a)$ of the samples were performed using AFM by randomly selecting three images per sample, each covering an area of $5 \mu \mathrm{m} \times 5 \mu \mathrm{m}$ in size. Mechanical strength was tested on cylindrical samples ( $\phi 5 \mathrm{~mm} \times 7.5 \mathrm{~mm}, n=5)$ in a universal material testing machine at a crosshead speed of $0.5 \mathrm{~mm} \cdot \mathrm{min}^{-1}$ (AGS-X, SHIMADZU, Japan).

\subsection{In vitro cell study}

Murine MC3T3-E1 pre-osteoblasts were selected as model to co-culture with the resulting HA ceramics, according to the previously reported procedures ${ }^{[28]}$. The cells were seeded onto the samples at a concentration of $1 \times 10^{4}$ cells per well and cultured in 24 -well plates. For morphological observations, the attached cells were fixed in $4 \%$ paraformaldehyde for $10 \mathrm{~min}$, and then washed for three times with phosphate buffered saline (PBS). The samples were treated with $0.5 \%$ Triton X-100 in PBS to permeabilize the cells for $5 \mathrm{~min}$, and then washed twice with PBS for $10 \mathrm{~min}$. The actin skeletons of the cells were labeled by incubating with Phalloidin-TRITC (Sigma) for $30 \mathrm{~min}$. After being rinsed with PBS, the cell nuclei were stained with blue by 4',6-diamidino-2-phenylin dole dihydrochloride (DAPI, Sigma), and visualized 
using a confocal laser scanning microscopy (CLSM, TCS SP5, Leica, German). Cell morphology was observed by SEM after $2 \mathrm{~d}$ of culture. Prior to observation, the samples were fixed in $1.5 \%$ glutaraldehyde for $12 \mathrm{~h}$, dehydrated in an alcohol concentration gradient $(30 \%$, $50 \%, 70 \%, 80 \%, 90 \%$ and $100 \%$ ), and dried by a critical-point drier (HCP-2, Hitachi, Japan). Cell viability was measured using cell counting kit-8 (CCK-8, Dojindo, Japan) at 1, 3 and $5 \mathrm{~d}$. At each time point, the media were removed, and fresh serum-free medium with $10 \% \mathrm{CCK}-8$ was added in each well. After incubation at $37{ }^{\circ} \mathrm{C}$ for $2 \mathrm{~h}$, the absorbance was measured at the wavelength of $450 \mathrm{~nm}$ in a microplate reader (Multiskan FC, America).

\subsection{Statistical analysis}

One-way analysis of variance by SPSS 11.0 software (SPSS Inc., USA) was used to perform the statistical analysis of the data. All of the quantitative results were obtained from at least triplicate measurements, and the data were all expressed as mean \pm standard deviation (SD). Values of $p<0.05$ were considered statistically significant.

\section{Results}

\subsection{Characteristics of the HA initial powder}

Fig. 1 shows the morphologies and phase compositions of various HA precursor powders. The crystals of both HA-40 (Fig. 1(A)) and HA-80 (Fig. 1(C)) presented the needle-like morphology, and the obvious agglomeration among the crystals could be observed. With the addition of PEG, the dispersity of the HA-40PEG powders was improved significantly (Fig. 1(B)). Compared with HA-40 and HA-80, HA-40PEG exhibited smaller crystal size. This was also verified by the particle size distribution tests (Fig. 1(D)). All of the three powders had narrow particle size distributions. Their $D_{50}$ values were $(124.62 \pm$ $28.71),(65.16 \pm 31.23)$ and $(221.50 \pm 48.82) \mathrm{nm}$, respectively. Specific surface areas of HA-40, HA-40PEG, and HA-80 were $(89.76 \pm 3.96),(81.40 \pm 0.66)$, and $(41.76 \pm 0.71) \mathrm{m}^{2} \cdot \mathrm{g}^{-1}$, respectively (Table 1 ).

Fig. 2(A) shows XRD patterns of three HA precursor powders. The diffraction peaks of each powder were well in line with those of HA standard (JCPDS 09-0432), indicating that they were composed of pure HA phase. Their crystallinities were also calculated and listed in Table 1 . It could be observed that the crystallinity of powder
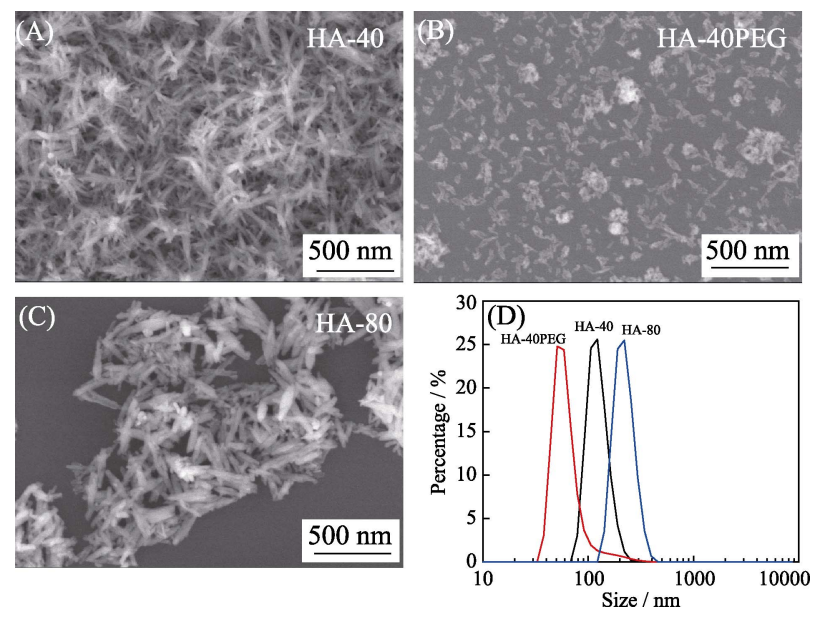

Fig. 1 (A-C) SEM images and (D) particle size distributions of various HA precursor powders

Table 1 Physicochemical properties of the three HA precursor powders

\begin{tabular}{cccccc}
\hline Sample & Particle size,$D_{50} / \mathrm{nm}$ & Crystallinity, $X_{\mathrm{c}} / \%$ & Specific surface area $/\left(\mathrm{m}^{2} \cdot \mathrm{g}^{-1}\right)$ & Crystallinity index & Maturity index \\
\hline HA-40 & $(124.62 \pm 28.71)$ & 31.76 & $(89.76 \pm 3.96)$ & 5.91 & 2.02 \\
HA-40PEG & $(65.16 \pm 31.23)$ & 39.48 & $(81.40 \pm 0.66)$ & 5.31 & 1.91 \\
HA-80 & $(221.50 \pm 48.82)$ & 77.94 & $(41.76 \pm 0.71)$ & 7.45 & 1.86 \\
\hline
\end{tabular}
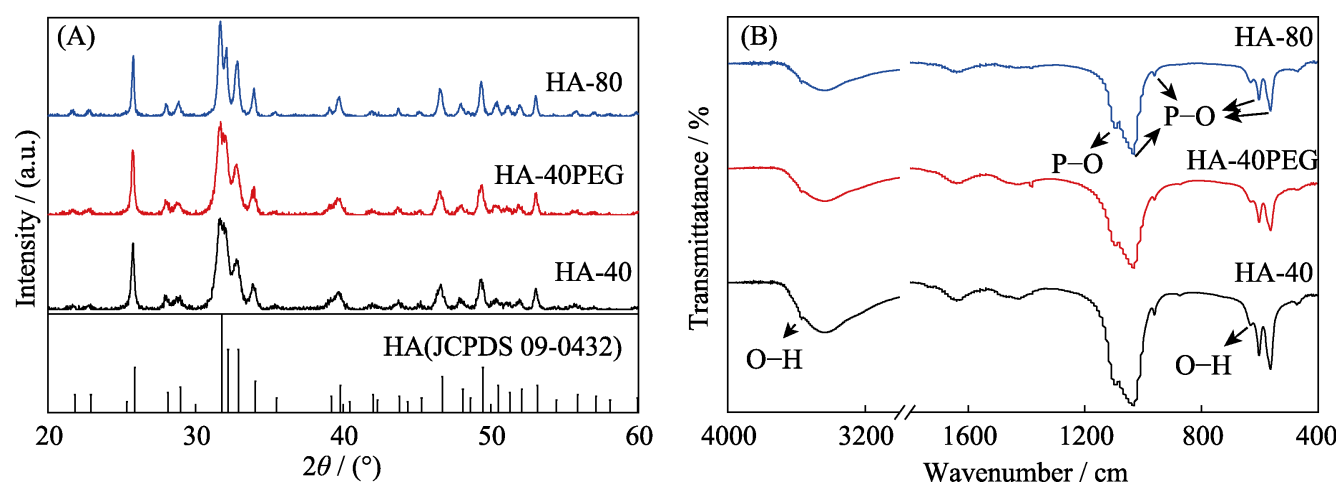

Fig. 2 (A) XRD patterns and (B) FT-IR spectra of HA initial powder (HA-40, HA-40PEG, HA-80) 
synthesized at $80{ }^{\circ} \mathrm{C}$ was the highest (77.94\%), followed by the powder of HA-40PEG (39.48\%). The powder synthesized at $40{ }^{\circ} \mathrm{C}$ showed the lowest crystallinity of $31.76 \%$. In addition, three kinds of powders exhibited similar FT-IR spectra (Fig. 2(B)). The bands at 602 and $563 \mathrm{~cm}^{-1}$ were assigned to the $\mathrm{P}-\mathrm{O}$ bending mode $(v 4)$, 1090 and $1037 \mathrm{~cm}^{-1}$ to asymmetric stretching mode (v3), and $962 \mathrm{~cm}^{-1}$ to symmetric stretching vibration $(v 1)$. The $\mathrm{O}-\mathrm{H}$ group stretching and vibrational bands at 3570 and $629 \mathrm{~cm}^{-1}$. No characteristic PEG peaks were found in HA-40PEG, indicating that the PEG had been washed out from the HA powders. The crystallinity index of each HA precursor powder is shown in Table 1. The crystallinity indexes of the powders HA-40, HA-40PEG and HA- 80 were $5.91,5.31$, and 7.45 , respectively. In general, the higher crystallinity index is, the larger and/or more ordered crystals $\operatorname{are}^{[26]}$. Likely, our results indicated that with lower crystallinity and smaller crystal size, the powder HA-40PEG had lower crystallinity index than the other two powders. The mineral maturity index of each HA precursor powder is shown in Table 1. It indicated that the maturity index of powder HA-40 was higher than the other two powders.

\subsection{Microstructures of HA ceramics}

Fig. 3(A) shows the SEM images of the obtained ceramics of HA-40, HA-40PEG and HA-80. All of the samples exhibited the typically ceramic morphology that obvious grain boundaries distributed among the ceramic grains. The grain size of HA-80 ((316.65 \pm 68.91$) \mathrm{nm}$, analyzed by Image-Pro Plus 6.0 software, Fig. 3(B)) was larger than that of HA-40 $((217.87 \pm 57.53) \mathrm{nm})$, indicating that the lower crystallinity of the powder might result in the HA ceramics with smaller grain size. Furthermore, the grain size of HA-40PEG was at nano-scale level ((123.22 \pm 20.16) $\mathrm{nm}$ ), the nanocrystalline might exert great influence on the property of the resulting HA ceramic. The XRD patterns (Fig. 3(C)) indicated that HA-40, HA-40PEG and HA- 80 were all composed of HA phase, and all of the three kinds of HA ceramics had relatively high crystallinity ( $>96 \%$, listed in Table 2$)$ by calculation. These results indicated that the HA initial powder synthesized with the addition of PEG and relatively low temperature was beneficial to the fabrication of HA nanoceramics.

\subsection{Surface property of HA ceramics}

AFM images of the three HA ceramics are shown in Fig. 4(A). It could be observed that the surface topographies of HA-40 and HA- 80 were relatively smoother than that of HA-40PEG. From the line profiles shown in
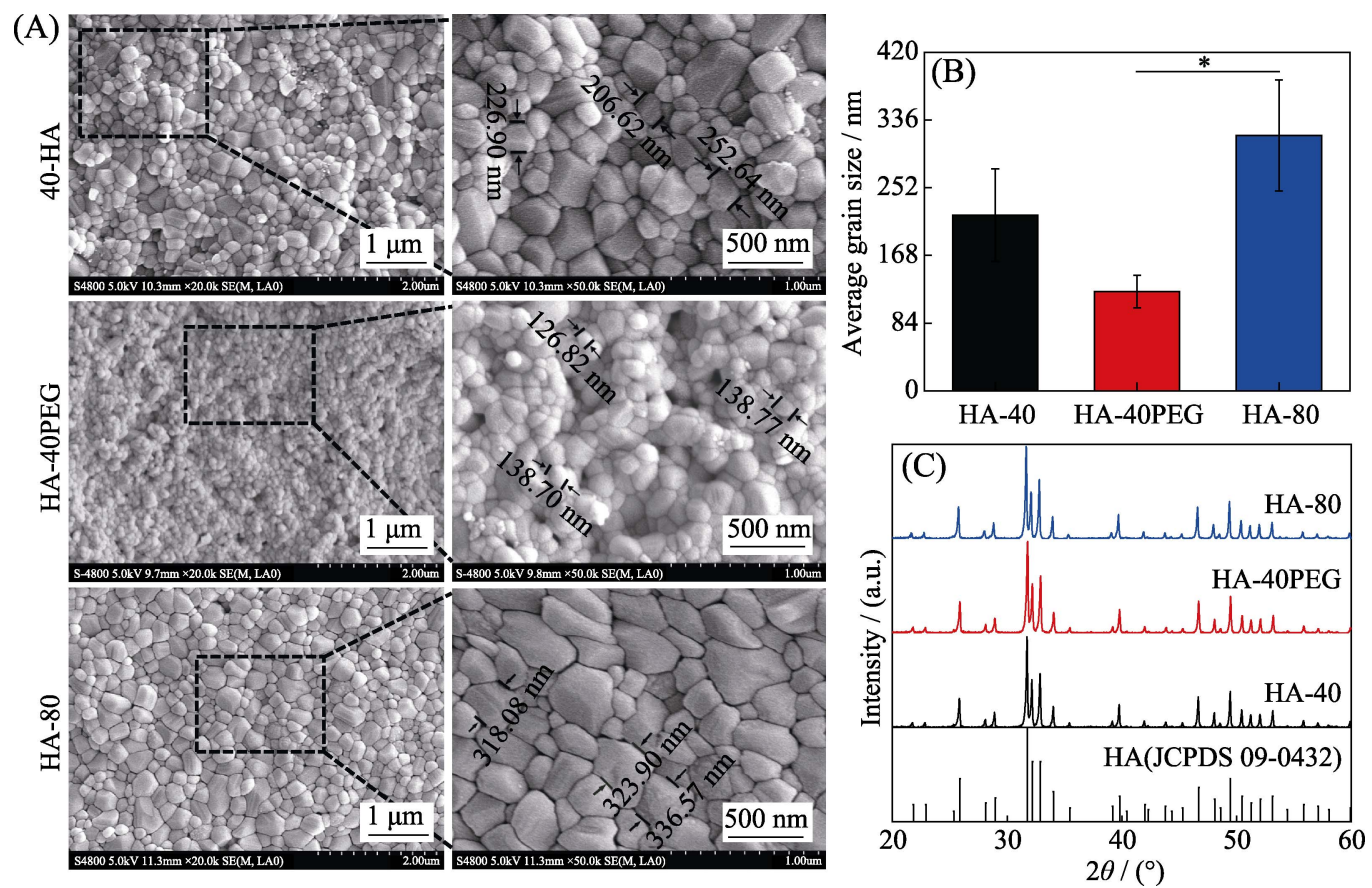

Fig. 3 (A) SEM images, (B) average grain sizes and (C) XRD patterns of the three kinds of HA ceramics (HA-40, HA-40PEG and HA-80)

Table 2 Physicochemical properties of the three HA ceramics

\begin{tabular}{cccccc}
\hline Sample & Crystallinity, $X_{\mathrm{c}} / \%$ & Surface roughness, $R_{\mathrm{a}} / \mathrm{nm}$ & Contact angle $/\left(^{\circ}\right)$ & Grain size $/ \mathrm{nm}$ & Relative density $/ \%$ \\
\hline HA-40 & 97.48 & $(61.49 \pm 5.65)$ & $(69.20 \pm 6.94)$ & $(217.87 \pm 57.53)$ & $(94.90 \pm 2.27)$ \\
HA-40PEG & 96.92 & $(66.70 \pm 2.81)$ & $(56.07 \pm 0.42)$ & $(123.22 \pm 20.16)$ & $(93.45 \pm 3.32)$ \\
HA-80 & 98.33 & $(57.81 \pm 3.44)$ & $(79.83 \pm 1.99)$ & $(316.65 \pm 68.91)$ & $(85.57 \pm 0.91)$ \\
\hline
\end{tabular}



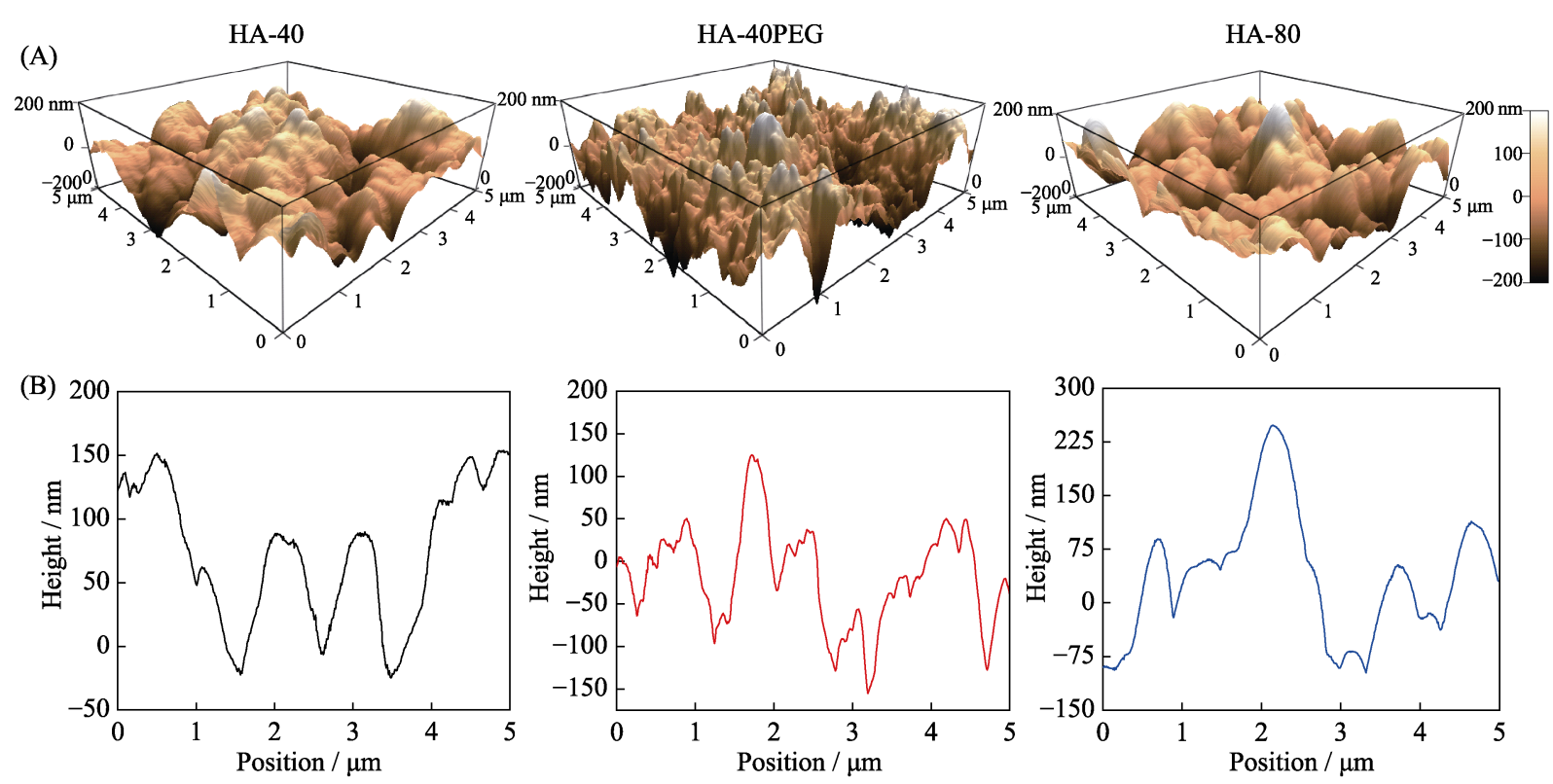

(C)
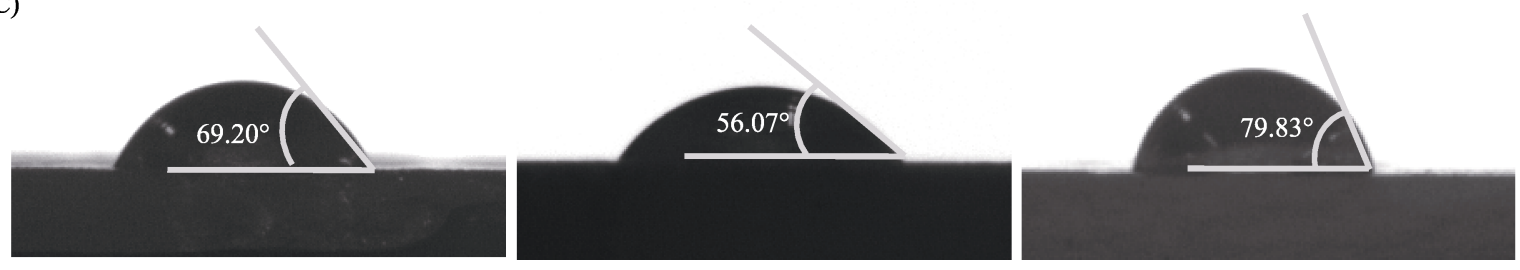

Fig. 4 (A) AFM topographies, (B) line profiles, (C) contact angles of the three kinds of HA ceramics (HA-40, HA-40PEG and HA-80)

Fig. 4(B), HA ceramics with nanocrystalline (HA-40PEG) exhibited larger fluctuation of surface morphology than the other two groups. The value of surface roughness was also calculated and list in Table 2. HA-40PEG with nanocrystalline had higher surface roughness $\left(R_{\mathrm{a}},(66.70 \pm\right.$ $2.81) \mathrm{nm})$ than HA-40 $((61.49 \pm 5.65) \mathrm{nm})$ and HA-80 $((57.81 \pm 3.44) \mathrm{nm})$. The contact angles of the HA ceramics are showed in Fig. 4(C). They were in the order of HA-40PEG $\left(56.07^{\circ} \pm 0.42^{\circ}\right)<$ HA- $40\left(69.20^{\circ} \pm 6.94^{\circ}\right)<$ HA- 80 $\left(79.83^{\circ} \pm 1.99^{\circ}\right)$. The different hydrophilicities of HA ceramics might be attributed to their different grain sizes and surface roughness.

\subsection{Mechanical strength of HA ceramics}

The mechanical strengths of HA ceramics mainly depended on their microstructure, such as grain size, densities, and so on. As shown in Fig. 5(A), HA-40 and HA-40PEG had higher relative densities $(\sim 95 \%)$ than HA-80 ( $85 \%)$, suggesting that the precursor powders synthesized at lower temperature was beneficial to obtain HA ceramics with higher density. All of the three kinds of HA ceramics exhibited typically brittle fracture from their strain-stress curves (Fig. 5(B)). HA-40PEG possessed higher compressive strength (Fig. 5(C)) and elastic modulus (Fig. 5(D)) than HA-40 and HA-80. The relatively high mechanical properties of HA-40PEG might be partly attributed to its small grain size and high density.

\subsection{Cell spreading and proliferation}

An excellent biomaterial should be also beneficial for cell adhesion and growth. After for $2 \mathrm{~d}$ of culturing, MC3T3-E1 exhibited a typical spindle-like morphology with outstretched filopodia to tightly grasp the ceramic grains from SEM images (Fig. 6(A)). As compared to HA-40 and HA-80, more filopodia were found in cells grown on HA-40PEG with nanocrystalline.

Quantitative analysis of cell morphology showed that cells attached on HA-40PEG had significantly larger cell area than those on HA-40 and HA-80 (Fig. 6(C)). The morphology of MC3T3-E1 grown on three kinds of HA ceramics was further stained with TRITC conjugatedphalloidin for cytoskeleton and observed by CLSM (Fig. 6(B)). The cells displayed elongated flatten morphology and began to contact with each other at $3 \mathrm{~d}$. CCK-8 results (Fig. 6(D)) indicated that obvious cell proliferation was observed on three kinds of HA ceramics, and the cell viabilities on HA-40 and HA-40PEG were higher than HA- 80 at $5 \mathrm{~d}$. These results suggested that HA with nanocrystalline was beneficial to the spreading and proliferation of MC3T3-E1.

\section{Discussion}

It is still a hot topic to seek a balance between the 

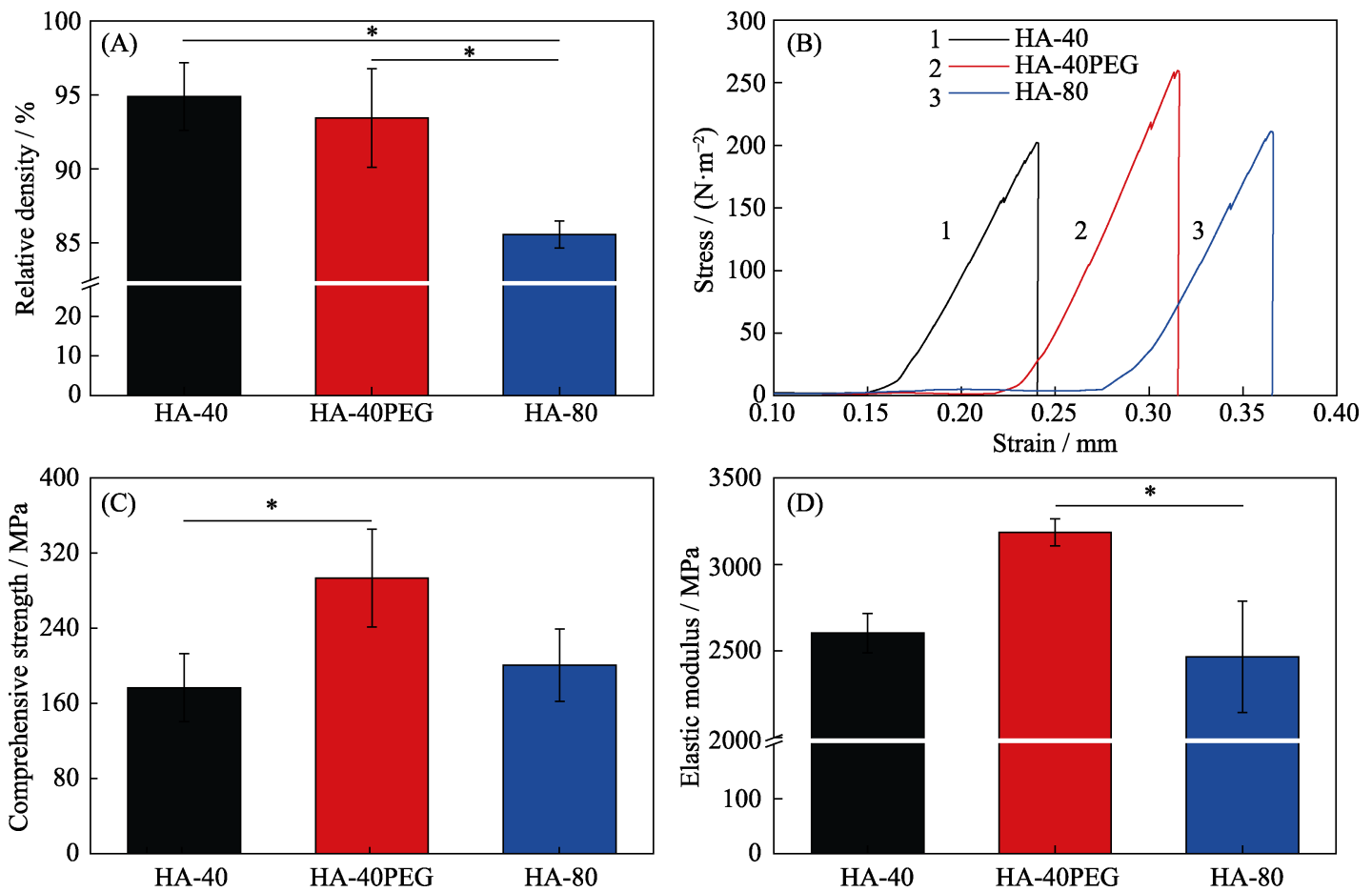

Fig. 5 (A) Relative densities, (B) strain-stress curves, (C) compressive strengths and (D) elastic modulus of the three kinds of HA ceramics (HA-40, HA-40PEG and HA-80)

Values are expressed as the mean $\pm \mathrm{SD}(n=3) ;{ }^{*} p<0.05$ and ${ }^{* *} p<0.01$

(A)
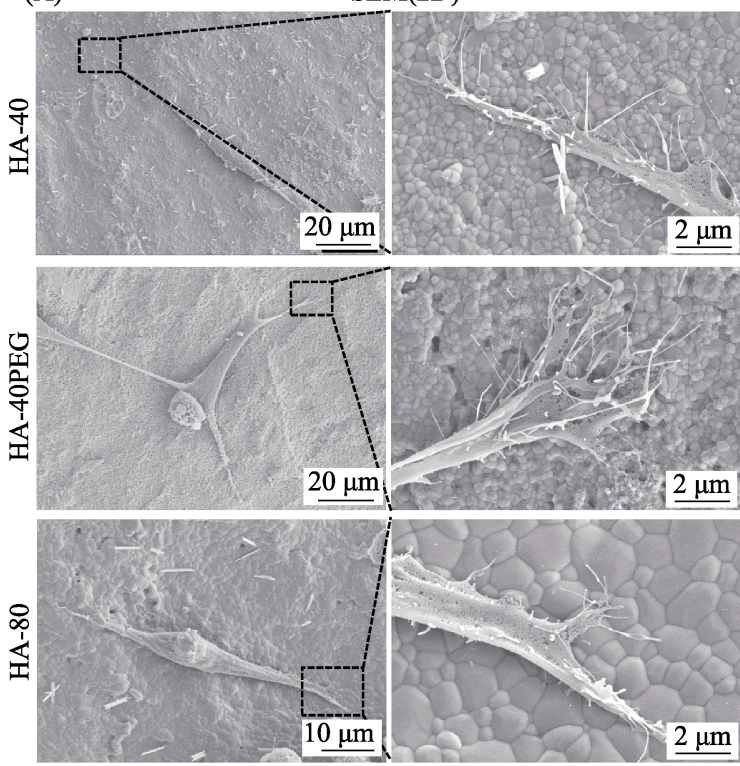

(B)
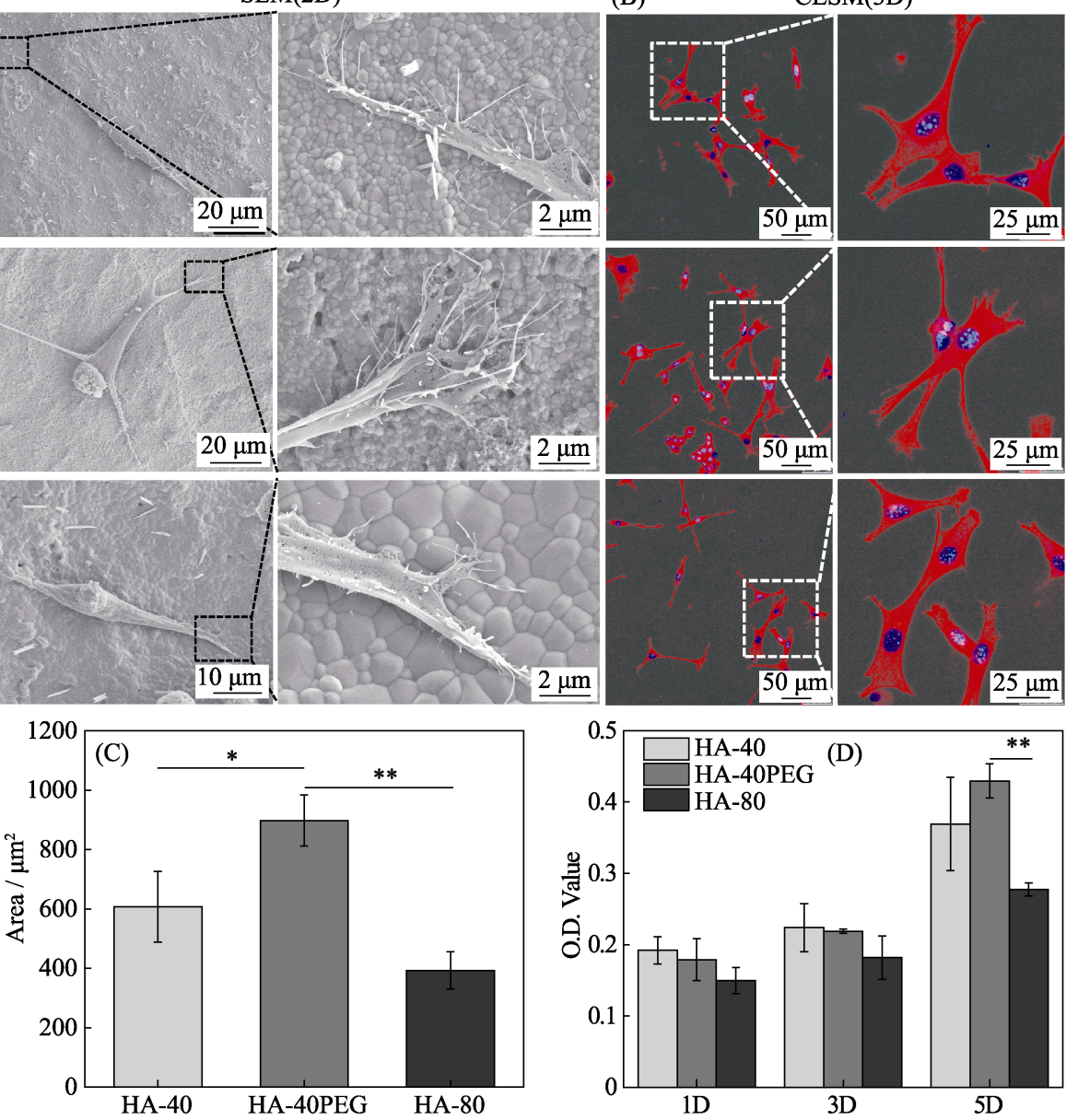

Fig. 6 (A) SEM images, (B) CLSM observations of cytoskeleton, (C) cell area, and (D) CCK-8 results of MC3T3-E1 cultured on HA ceramics

Values are expressed as the mean $\pm \mathrm{SD}(n=3) ;{ }^{*} p<0.05$ and ${ }^{* *} p<0.01$ 
simultaneous enhancements of mechanical strength and biological property in HA ceramics. Construction of nanoceramics may be an effective way to solve this problem. In the previous studies, the nanoceramics exhibited the higher mechanical properties in compress strength, fracture toughness and hardness than microceramics ${ }^{[29-30]}$. However, the influence of the precursor powders on the preparation of HA nanoceramics was rarely studied. Up to now, there have been many methods to prepare the HA precursor powders, including hydrothermal method, Sol-Gel method, wet chemical precipitation method and so on. Among them, wet chemical precipitation seems to be the most suitable one, due to its simple operation, stable reaction and high yield. Besides, the aggregation of the particles can be well overcome by adding organic dispersants. However, the properties of the obtained HA nanoceramics need to be further optimized, especially their advantages of mechanical property have not been fully exploited. Therefore, the present study mainly discussed the effect of the precursor powders on the properties of HA nanoceramics, and investigated their efficiency in the mechanical property and cellular viability.

In this study, three kinds of HA precursor powders were firstly synthesized at different temperatures and with PEG addition by employing wet chemical precipitation method. Comparing with HA-40 and HA-80, HA-40PEG synthesized at low temperature $\left(40{ }^{\circ} \mathrm{C}\right)$ with $\mathrm{PEG}$ addition owned smaller grain size, which contributed to the densification of the resulting ceramic in the sintering process. And the powder with low crystallinity and high specific surface area was suitable for the fabrication of HA nanoceramics $^{[31-34]}$. Owing to these desirable properties of precursor powders, HA-40PEG ceramic exhibited good nanocrystalline structure, and had higher density ( 95\%) than the other two HA ceramics.

The mechanical strength of HA ceramics was mainly influenced by their compactness and grain size. When the grain size decreased to nanoscale, the number of grain boundaries and the crack deflections increased (from transgranular fracture to intergranular fracture). Therefore, the nanoceramics can offer more resistance to crack propagation and dislocation motion, and exhibit higher compressive strength and elastic modulus than the submicro ones ${ }^{[4,30]}$. HA-40PEG ceramics had the nanograins, and then showed the highest mechanical strength among three HA ceramics. Additionally, the mechanical strength of a ceramic is highly dependent on its compactness, because it changes the effective or critical load-bearing area of the specimen ${ }^{[35]}$. Thus, the low relative density of HA-80 could further deteriorate its mechanical properties.

The surface morphology, surface roughness and hydrophilicity are important properties to biomaterials. The grain size of a material would influence the surface properties, such as surface area, charge and topography ${ }^{[1]}$. In the present study, the surface roughness of HA-40PEG was higher than those of HA-40 and HA-80, due to the different grain sizes in the ceramics. Thus, the surface roughness of HA-40PEG was higher than that of HA-40 and HA-80. Moreover, the rougher surface could provide larger surface area, which contributes to enhance the hydrophilicity of the ceramics ${ }^{[36]}$. Thus, HA-40PEG exhibited the lowest contact angle among three HA ceramics.

The relatively high surface roughness and hydrophilicity of HA-40PEG with nanocrystalline would have beneficial effects on the improvement of the bioactivity. When the grain size of HA ceramics decreased from micro-scale to nano-scale, cell adhesion mainly depended on the topography of the nanoceramics rather than surface chemistry ${ }^{[37-38]}$. From the in vitro cell experimental results, the MC3T3-E1cells showed more filopodia and larger spreading area on HA-40PEG than HA-40 and HA-80, indicating that HA nanoceramics could enhance the cell attachment and spreading. As discussed previously, surface area, surface energy and grain boundary of the HA ceramics increased with the decrease in the grain size ${ }^{[39]}$. HA nanoceramics could provide more binding sites for cell adhesion, and then influenced the cellular morphology and proliferation ${ }^{[40-42]}$.

\section{Conclusions}

Overall, the present study focused on the construction of HA nanoceramics by optimizing the precursor powders, and investigated their mechanical strengths and biological properties. The addition of PEG and relatively low reaction temperature were beneficial to obtain HA powders with small grain size and well dispersity, which was suitable for the fabrication of HA nanoceramics with high density and enhanced mechanical property. Because of the nanotopography, HA-40PEG exhibited relatively higher surface roughness and better hydrophilicity than the submicro ceramics, which promoted the cell adhesion and spreading. These findings highlight that the optimization of the precursor powder plays an important role in the fabrication of HA nanoceramics, which has a certain guiding significance for preparing HA bioceramics with simultaneous enhancement of mechanical strength and bioactivity.

\section{References:}

[1] HONG Y, FAN H, LI B, et al. Fabrication, biological effects, and medical applications of calcium phosphate nanoceramics. Materials Science \& Engineering R, 2010, 70(3): 225-242.

[2] DOROZHKIN S V. Calcium orthophosphates in nature. Biology 
and Medicine Materials, 2009, 2(1): 399-498.

[3] NASIRI-TABRIZI B, HONARMANDI P, EBRAHIMI-KAHRIZSANGI $\mathrm{R}$, et al. Synthesis of nanosize single-crystal hydroxyapatite via mechanochemical method. Materials Letters, 2009, 63(5): 543-546.

[4] WANG J, SHAW L L. Nanocrystalline hydroxyapatite with simultaneous enhancements in hardness and toughness. Biomaterials, 2009, 30(34): 6565-6572.

[5] BOSE S, DASGUPTA S, TARAFDER S, et al. Microwave-processed nanocrystalline hydroxyapatite: simultaneous enhancement of mechanical and biological properties. Acta Biomater., 2010, 6(9): 3782-3790.

[6] FANG Z, FENG Q, TAN R. In-situ grown hydroxyapatite whiskers reinforced porous HA bioceramic. Ceramics International, 2013, 39(8): 8847-8852.

[7] PROKOPIEV O, SEVOSTIANOV I. Dependence of the mechanical properties of sintered hydroxyapatite on the sintering temperature. Materials Science \& Engineering A, 2006, 431(1): 218-227.

[8] HABIBOVIC P, YUAN H, VAN DER VALK C M, et al. 3D microenvironment as essential element for osteoinduction by biomaterials. Biomaterials, 2005, 26(17): 3565-3575.

[9] KIM H M, HIMENO T, KOKUBO T, et al. Process and kinetics of bonelike apatite formation on sintered hydroxyapatite in a simulated body fluid. Biomaterials, 2005, 26(21): 4366-4373.

[10] RICE R W, WU C C, BOICHELT F. Hardness-grain-size relations in ceramics. Journal of the American Ceramic Society, 1994, 77(10): 2539-2553.

[11] MOSHTAGHIOUN B M, GOMEZ-GARCIA D, DOMINGUEZRODRIGUEZ A, et al. Grain size dependence of hardness and fracture toughness in pure near fully-dense boron carbide ceramics. Journal of the European Ceramic Society, 2016, 36(7): 1829-1834.

[12] GU Y W, LOH N H, KHOR K A, et al. Spark plasma sintering of hydroxyapatite powders. Biomaterials, 2002, 23(1): 37-43.

[13] KIM B N, PRAJATELISTIA E, HAN Y H, et al. Transparent hydroxyapatite ceramics consolidated by spark plasma sintering. Scripta Materialia, 2013, 69(5): 366-369.

[14] GUO X, XIAO P, JING L, et al. Fabrication of nanostructured hydroxyapatite via hydrothermal synthesis and spark plasma sintering. Journal of the American Ceramic Society, 2005, 88(4): 1026-1029.

[15] RAMESH S, TAN C Y, BHADURI S B, et al. Rapid densification of nanocrystalline hydroxyapatite for biomedical applications. Ceramics International, 2007, 33(7): 1363-1367.

[16] VELJOVIC D, JOKIC B, PETROVIĆ R, et al. Processing of dense nanostructured HAP ceramics by sintering and hot pressing. Ceramics International, 2009, 35: 1407-1413.

[17] WANG J, SHAW L L. Transparent nanocrystalline hydroxyapatite by pressure-assisted sintering. Scripta Materialia, 2010, 63(6): 593-596.

[18] CHEN I W, WANG X H. Sintering dense nanocrystalline ceramics without final-stage grain growth. Nature, 2000, 404(6774): 168-171.

[19] LIN K, CHEN L, CHANG J. Fabrication of dense hydroxyapatite nanobioceramics with enhanced mechanical properties via two-step sintering process. International Journal of Applied Ceramic Technology, 2012, 9(3): 479-485.

[20] LUKIĆ M J, ŠKAPIN S D, MARKOVIĆ S, et al. Processing route to fully dense nanostructured HAp bioceramics: from powder synthesis to sintering. Journal of the American Ceramic Society, 2012, 95(11): 3394-3402.

[21] THUAULT A, SAVARY E, HORNEZ J C, et al. Improvement of the hydroxyapatite mechanical properties by direct microwave sintering in single mode cavity. Journal of the European Ceramic Society, 2014, 34(7): 1865-1871.

[22] LI X, SONG T, CHEN X, et al. Osteoinductivity of porous biphasic calcium phosphate ceramic spheres with nanocrystalline and their efficacy in guiding bone regeneration. ACS Applied Materials \& Interfaces, 2019, 11(4): 3722-3736.

[23] LIU D, WU Y, WU H, et al. Effect of process parameters on the microstructure and property of hydroxyapatite precursor powders and resultant sintered bodies. International Journal of Applied Ceramic Technology, 2018, 16(2): 444-454.

[24] SONG J, YONG L, YING Z, et al. Mechanical properties of hydroxyapatite ceramics sintered from powders with different morphologies. Materials Science \& Engineering A, 2011, 528(16/17): 5421-5427.

[25] LANDI E, TAMPIERI A, CELOTTI G, et al. Densification behaviour and mechanisms of synthetic hydroxyapatites. Journal of the European Ceramic Society, 2000, 20(14): 2377-2387.

[26] WEINER S, BAR-YOSEF O. States of preservation of bones from prehistoric sites in the Near East: a survey. Journal of Archaeological Science, 1990, 17(2): 187-196.

[27] FARLAY D, PANCZER G, REY C, et al. Mineral maturity and crystallinity index are distinct characteristics of bone mineral. Journal of Bone and Mineral Metabolism, 2010, 28: 433-445.

[28] LI X, DENG Y, WANG M, et al. Stabilization of Ca-deficient hydroxyapatite in biphasic calcium phosphate ceramics by adding alginate to enhance their biological performances. Journal of Materials Chemistry B, 2017, 6(1): 84-97.

[29] MAZAHERI M, HAGHIGHATZADEH M, ZAHEDI A M, et al. Effect of a novel sintering process on mechanical properties of hydroxyapatite ceramics. Journal of Alloys \& Compounds, 2009, 471(1): $180-184$

[30] DASGUPTA S, TARAFDER S, BANDYOPADHYAY A, et al. Effect of grain size on mechanical, surface and biological properties of microwave sintered hydroxyapatite. Materials Science \& Engineering C Materials for Biological Applications, 2013, 33(5): 2846-2854.

[31] PANG Y X, BAO X. Influence of temperature, ripening time and calcination on the morphology and crystallinity of hydroxyapatite nanoparticles. Journal of the European Ceramic Society, 2003, 23(10): 1697-1704.

[32] KUMAR R, PRAKASH K, CHEANG P, et al. Temperature driven morphological changes of chemically precipitated hydroxyapatite nanoparticles. Langmuir, 2004, 20: 5196-5200.

[33] TSENG Y H, KUO C S, LI Y Y, et al. Polymer-assisted synthesis of hydroxyapatite nanoparticle. Materials Science and Engineering: C, 2009, 29(3): 819-822.

[34] LI H, XUE F, WAN X, et al. Polyethylene glycol-assisted preparation of beta-tricalcium phosphate by direct precipitation method. Powder Technology, 2016, 301: 255-260.

[35] AKAO M, AOKI H, KATO K. Mechanical properties of sintered hydroxyapatite for prosthetic applications. Journal of Materials Science, 1981, 16: 809-812.

[36] ARIFVIANTO B, MAHARDIKA M, DEWO P, et al. Effect of surface mechanical attrition treatment (SMAT) on microhardness, surface roughness and wettability of AISI 316L. Materials Chemistry and Physics, 2011, 125(3): 418-426.

[37] DOS SANTOS E, FARINA M, SOARES G, et al. Surface energy of hydroxyapatite and $\beta$-tricalcium phosphate ceramics driving serum protein adsorption and osteoblast adhesion. Journal of Materials Science: Materials in Medicine, 2008, 19(6): 2307-2316.

[38] LI B, CHEN X, GUO B, et al. Fabrication and cellular biocompatibility of porous carbonated biphasic calcium phosphate ceramics with a nanostructure. Acta Biomaterialia, 2009, 5(1): 134-143.

[39] GUO X, GOUGH J E, XIAO P, et al. Fabrication of nanostructured hydroxyapatite and analysis of human osteoblastic cellular 
response. Journal of Biomedical Materials Research Part A, 2007, 82(4): 1022-1032.

[40] MICHIARDI A, APARICIO C, RATNER B D, et al. The influence of surface energy on competitive protein adsorption on oxidized NiTi surfaces. Biomaterials, 2007, 28(4): 586-594.
[41] YAO C, PERLA V, MCKENZIE J L, et al. Anodized Ti and $\mathrm{Ti}_{6} \mathrm{Al}_{4} \mathrm{~V}$ possessing nanometer surface features enhances osteoblast adhesion. Journal of Biomedical Nanotechnology, 2005, 1(1): 68-73.

[42] WEBSTER T J, SIEGEL R W, BIZIOS R. Osteoblast adhesion on nanophase ceramics. Biomaterials, 1999, 20(13): 1221-1227.

\title{
高强度羟基磷灰石纳米陶瓷的构建及其 促成骨细胞活性研究
}

\author{
吴永豪，李向锋，朱向东，张兴栋 \\ (四川大学 国家生物医学材料工程技术研究中心，成都 610064)
}

摘 要: 本研究旨在研究羟基磷灰石 $(\mathrm{HA})$ 前驱粉体与所制备陶瓷之间的关系, 制备具有优良力学性能及成骨活性的 $\mathrm{HA}$ 纳米陶瓷。采用三种 $\mathrm{HA}$ 前驱粉体, 即 $40{ }^{\circ} \mathrm{C}$ 合成的 HA-40 粉体、以 PEG 为模板 $40{ }^{\circ} \mathrm{C}$ 合成的 HA-40PEG 粉体 和 $80{ }^{\circ} \mathrm{C}$ 合成的 HA-80 粉体, 系统研究了前驱粉体对陶瓷性能的影响。结果显示, HA-40、HA-40PEG 和 HA-80 粉 体制备的陶瓷晶粒尺寸分别为(217.87 \pm 57.53$) 、(123.22 \pm 20.16)$ 和(316.65 568.91$) \mathrm{nm}$, 表明 HA-40PEG 有利于 HA 纳 米陶瓷的制备。烧结得到的 HA-40PEG 纳米晶陶瓷表现出良好的力学性能, 与另外两种亚微米晶陶瓷(HA-40 和 HA-80)相比, 其抗压强度更高( 300 MPa)。细胞研究结果显示, HA-40PEG 比 HA-40 和 HA-80 更能促进 MC3T3-E1 前成骨细胞的铺展和增殖。由此可知, 前驱粉体合成是影响 HA 陶瓷性能的关键因素, 纳米晶构建有利于同时提高 其力学性能和生物学性能。

关 键 词: 羟基磷灰石; 纳米陶瓷; 前驱粉体; 致密度; 细胞活力

中图分类号: TQ174 文献标志码: A 